\title{
EGFR mutations in malignant pleural effusions from lung cancer
}

\author{
Clayton J. Shamblin • Nichole T. Tanner • \\ Rolando Sanchez Sanchez • Julie A. Woolworth • \\ Gerard A. Silvestri \\ Published online: 14 March 2013 \\ (C) Springer Science+Business Media New York 2013
}

\begin{abstract}
A malignant pleural effusion (MPE) from lung cancer represents stage IV disease and portends a poor prognosis. Routine mutational analysis of tissue samples is the standard of care in advanced lung cancer management because it has treatment implications. Sampling of MPE is minimally invasive, safe, repeatable, and provides both diagnostic and therapeutic value. Mutational analysis on MPE has been shown to be feasible and correlates with a response to targeted therapy with tyrosine kinase inhibitors (TKIs). Guidelines recommend mutational testing in MPE, however there is no one standardized method for testing. There are several testing methods available for mutational analysis in pleural fluid including PCR, mutant-enriched PCR, DNA \& RNA sequencing, and immunohistochemistry the sensitivity of which are dependent upon tumor cell heterogeneity. The advantages and disadvantages of each will be reviewed here.
\end{abstract}

Keywords Epidermal growth factor receptor (EGFR) . Malignant pleural effusion · Non-small cell lung cancer (NSCLC) · Tyrosine kinase inhibitors (TKIs) ·

Molecular testing

C. J. Shamblin • N. T. Tanner • R. S. Sanchez $\cdot$ G. A. Silvestri $(\bowtie)$ Department of Medicine, Division of Pulmonary and Critical Care, Medical University of South Carolina, PO Box 250630

Charleston, SC 29425, USA

e-mail: silvestri@musc.edu

C. J. Shamblin

e-mail:shamblc@musc.edu

N. T. Tanner

e-mail: tripici@musc.edu

\section{J. A. Woolworth}

Department of Pathology and Laboratory Medicine, Medical

University of South Carolina, Charleston, SC, USA

\section{Introduction}

Lung cancer is the leading cause of cancer-related deaths worldwide with an estimated five-year survival rate of $16 \%$ for all comers [1]. Efficacy of traditional platinum-based two drug therapy for advanced stage non-small cell lung cancer (NSCLC) has plateaued with an overall response rate between 25 and $35 \%$ and median overall survival of 8 10 months [2]. Recent advances in molecular testing for epidermal growth factor receptor (EGFR) mutations, however, has allowed for the identification of a subset of patients that will be more responsive to therapy with targeted tyrosine kinase inhibitors (TKIs) [3-5]. This evolution toward individualized treatment has made it essential to further differentiate NSCLC based on these molecular aberrations, as it has significant treatment implications including improved survival. TKIs are recommended as first line therapy for stage 4 NSCLC with an EGFR positive mutation $[6 \bullet, 7]$ Because patients with metastatic disease are unlikely to undergo surgery, molecular testing of samples obtained using minimally invasive techniques has become important.

Malignant pleural effusion (MPE) from lung cancer is common and signifies advanced disease with median survival of 4 months [8]. Based upon poor prognostic implications, MPE has been reclassified to represent stage IV disease in the most recent iteration of the staging guidelines [9]. This article will review the pathophysiology of MPE, the role of targeted TKIs, methods for EGFR mutational analysis in MPEs, guidelines for mutational analysis testing, and will discuss future directions.

\section{Pathophysiology}

A pleural effusion develops when the production of pleural fluid exceeds its removal. One of the most common causes of effusion associated with impaired removal of pleural fluid 
is MPE, defined as a pleural effusion that occurs in the context of malignant invasion of the pleura. MPE can be diagnosed by detection of malignant cells in pleural fluid, pleural biopsy, or by direct visualization and biopsy using thoracoscopy/thoracotomy [10]. Tumor cells can invade the pleural space by direct extension from an adjacent tumor, invasion of the pulmonary vasculature with embolization to the visceral pleura, or through hematogenous metastasis from distal tumors to the parietal pleural. Once malignant cells invade the pleural space, they deposit on the parietal pleural membrane and obstruct the lymphatic stomata, disrupting the drainage of pleural fluid [10].

MPE is also related to an increase of pleural fluid production from fluid extravasation through hyperpermeable pleural vasculature. This increased permeability is a result of vasoactive mediators, including vascular endothelial growth factor (VEGF), tumor necrosis factor (TNF), osteopontin (OPN), and chemokine ligand 2 (CLL-2) produced by tumor cells in interaction with the normal mesothelial, endothelial and inflammatory cells [11, 12]. These vasoactive mediators have been targeted as diagnostic, prognostic biologic markers, and as potential targets for treatment $[12,13]$. In a recent meta-analysis aimed at determining the overall accuracy of pleural VEGF assays in diagnosing MPE, the sensitivity, specificity, positive likelihood ratio and negative likelihood were $75 \%, 72 \%, 2.94$ and 0.38 , respectively [14]. These findings suggest that determining pleural fluid VEGF may improve the accuracy of MPE diagnosis.

A paramalignant effusion is defined as cytologically negative pleural effusion in a patient with a known malignancy in the same lung. This occurs as a result of tumor invasion of the pleural fluid drainage system; anywhere between the lung lymphatic system and the mediastinal lymph nodes. Parapneumonic effusions may also result from complications related to the disease including bronchial obstruction, pulmonary embolism, or decreased oncotic pressure due to severe hypoalbuminemia. They can also arise as a result of therapies, including radiation and chemotherapy [10].

\section{Staging and prognostic implications in NSCLC}

Metastatic pleural extension of NSCLC includes the presence of malignant pleural nodules (which can be localized or diffuse-carcinomatosis), and/or malignant pleural effusion. Metastatic pleural extension has been reported in 1-7 \% of patients with NSCLC, and in $10 \%$ of patients with metastatic disease. It carries a poor prognosis and precludes a surgical resection $[9,15]$.

In 2002, the $6^{\text {th }}$ edition of the TNM classification of lung cancer classified malignant pleural extension in NSCLC as T4 (Stage IIIB). The International Association for the Study of Lung Cancer (IASLC) later conducted a large retrospective study using a validated database of 81,015 lung cancer cases between 1990 and 2000 from 46 institutions, 19 countries, and three continents. It was found that patients with malignant pleural extension $(N=771)$ had a median survival of 8 months and a 5 -year survival of $2 \%$ (very similar to the patients with intra-thoracic metastasis) $[9,15]$. A study of 23,583 patients with NSCLC from the California Cancer Registry demonstrated similar outcomes in patients with malignant pleural extension of NSCLC (5-year survival $3.1 \%$, median survival 4 months) [16]. Based on these findings, the presence of pleural nodules or malignant pleural effusion in patients with NSCLC was upstaged to M1a (Stage IV) in the 7th edition of the TNM classification of lung cancer, published in 2009.

The presence of MPE also appears to be an independent predictor of worse survival in those with stage IV disease due to extra-thoracic metastasis (median overall survival of 3 months versus 5 months in patients without MPE) [17]. Wu et al. recently found that in patients with stage IV lung adenocarcinoma $(N=448)$, those who present with MPE at the time of diagnosis have worse median overall survival compared to those who developed the MPE later in the course of their disease (14.3 versus 21.4 months, $p=0.001$ ) [18].

\section{Tyrosine kinase inhibitors and lung cancer}

Over the past several years, advances in molecular and cellular biology have led to a better understanding of the molecular pathogenesis of cancer. This has guided the development of therapeutic agents that target molecular pathways specific to malignant cells and therefore result in less toxicity to normal cells than conventional therapies. One of the best-studied pathways of oncogenic transformation in lung cancer cells is the activation of intracellular signal transduction pathways regulated by tyrosine kinases. Known variants in EGFR, the anaplastic lymphoma kinase (ALK), and Kirsten rat sarcoma (KRAS) are responsible for lung cancer cell proliferation, invasion and dissemination and the molecular targets approved therapeutic agents for the treatment of NSCLC [19].

Several drugs that target and inhibit these tyrosine kinase pathways have been developed and tested in patients with NSCLC. Gefitinib, Erlotinib, and Afatinib are EGFR tyrosine kinase inhibitors (EGFR-TKIs) that have shown significant improvement in progression-free survival compared to conventional chemotherapy in phase 3 trials as first line therapy in those with advanced NSCLC with activating EGFR mutations (Table 1) [20-25, 26•, 28].

The most common toxicity associated to the EGFR-TKIs is manifested in the skin, gastrointestinal (GI) tract and the 
Table 1 Phase III studies comparing EGFR TKIs versus platinum-based chemotherapy as first-line treatment of advanced NSCLC

\begin{tabular}{|c|c|c|c|}
\hline Study & Treatment & HR for progression $(95 \% \mathrm{CI})$ & $\mathrm{RR}, \%$ \\
\hline IPASS $(N=1,217)[6 \bullet]$ & Gefitinib vs. carboplatin/gemcitabine & $\begin{array}{l}\text { Overall: } 0.74(0.65-0.85)^{\mathrm{a}} \\
E G F R \text {-mut pos: } 0.48(0.36-0.64)^{\mathrm{a}} \\
E G F R \text {-mut neg: } 2.85(2.05-3.98)^{\mathrm{a}}\end{array}$ & $\begin{array}{l}\text { Overall: } 43.0 \text { vs. } 32.2^{\mathrm{e}} \\
\text { EGFR-mut pos: } 71.2 \text { vs. } 47.3^{\mathrm{e}} \\
\text { EGFR-mut neg: } 1.1 \text { vs. } 23.5^{\mathrm{b}}\end{array}$ \\
\hline First-SIGNAL $(N=309)[22]$ & Gefitinib vs. cisplatin/gemcitabine & $\begin{array}{l}\text { Overall: } 0.737(0.580-0.938)^{\mathrm{b}} \\
\text { Gefitinib }(E G F R-\text { mut neg vs. } E G F R- \\
\text { mut pos): } 0.385(0.208-0.711)^{\mathrm{b}} \\
\text { CT }(E G F R \text {-mut neg vs. } E G F R \text {-mut pos): } \\
1.223(0.650-2.305)^{\mathrm{c}}\end{array}$ & Overall: 53.5 vs. $42.0^{\mathrm{c}}$ \\
\hline WJTOG3405 $(N=172)[24]$ & Gefitinib vs. cisplatin/docetaxel & $0.489(0.336-0.710)^{\mathrm{a}}$ & 62.1 vs. $32.2^{\mathrm{a}}$ \\
\hline NEJ002 $(N=228)[23]$ & Gefitinib vs. carboplatin/ paclitaxel & $0.30(0.22-0.41)^{\mathrm{d}}$ & 73.7 vs. $30.7^{\mathrm{d}}$ \\
\hline OPTIMAL $(N=154)[27]$ & Erlotinib vs. carboplatin/ gemcitabine & $0.164(\mathrm{NR})^{\mathrm{a}}$ & 83 vs. $36^{\mathrm{a}}$ \\
\hline EURTAC $(N=174)[26 \bullet]$ & $\begin{array}{l}\text { Erlotinib vs. platinum-based } \\
\text { chemotherapy }\end{array}$ & $0.37(0.25-0.54)^{\mathrm{a}}$ & 64 vs. $18^{\mathrm{a}}$ \\
\hline LUX-Lung $3(N=345)[28]$ & Afatinib vs. pemetrexed/cisplatin & $0.47(0.34-0.65)^{\mathrm{a}}$ & 56 vs. $23^{a}$ \\
\hline
\end{tabular}

$C I$ confidence interval; $C T$ chemotherapy; EGFR epidermal growth factor receptor; EGFR-mut pos EGFR-mutation positive; EGFR-mut neg $E G F R$-mutation negative; $H R$ hazard ratio; $N R$ not reported; TKIs tyrosine kinase inhibitors

${ }^{\mathrm{a}} P<0.0001$

${ }^{\mathrm{b}} P<0.01$

${ }^{\mathrm{c}} P>0.05$

${ }^{\mathrm{d}} P<0.001$

${ }^{\mathrm{e}} P=0.0001$

lungs. In the skin, an acneiform rash and dry skin are the most frequent reported side effects (up to $55 \%$ in patients taking gefitinib) [29]. In the GI tract, diarrhea is reported in up to $60 \%$ of patients taking erlotinib [30,31]. In addition, there are case reports of GI perforation associated with the use of erlotinib, as well as hepatic failure in patients treated with erlotinib [30, 31]. Less commonly, erlotinib and gefitinib have been associated with interstitial pneumonitis.

Unfortunately, almost all patients who initially respond to an EGFR- TKIs subsequently develop resistance and experience progression of the disease [32]. Secondary mutations in EGFR (T790M, D761Y, and L747S) and amplification of the hepatocyte growth factor (cMET) oncogene appear to be responsible for the majority of cases of acquired resistance to EGFR-TKIs [32-35]. The T790M mutation is the most common secondary mutation, detected in approximately $50 \%$ of patients with acquired EGFR-TKI resistance [32]. Amplification of the cMET oncogene has been associated with resistance to EGFR TKIs in 5-20\% of disease progression while on treatment with erlotinib or gefitinib [35].

Despite the eventual progression of disease with EGFRTKIs, treatment guidelines recommend molecular testing for EGFR mutations in those diagnosed with advanced (stage 4) adenocarcinoma NSCLC, because targeted therapy significantly prolongs progression-free survival. While larger tissue samples are preferable, the majority of patients with stage IV NSCLC will not undergo surgical resection, and thus diagnostic approaches have shifted toward minimally invasive procedures [36]. Techniques have therefore been developed whereby molecular testing can be performed on lesser amounts of tissue, and specific criteria for sample type, size, collection and storage have previously been published [36]. Cytologic analysis of pleural fluid is an attractive alternative to tissue acquisition, as it has the potential to simultaneously yield a diagnosis and a stage. Tumor cells obtained from the pleural fluid may also be tested for EGFR mutations. Furthermore, a higher rate of EGFR mutations have been demonstrated in patients with a MPE associated with lung adenocarcinoma [37].

\section{MPE and EGFR}

Although the literature concerning EGFR-positive NSCLC and its response to TKI therapy is broad, the number of studies focusing on EGFR positivity in pleural involvement has been less robust [38]. Based upon data from ten such studies, the incidence of EGFR mutation rates in MPE appears to range from $24-68.7 \%$, with a median rate of $34 \%$ [37, 39-47]. Additionally, several of these studies indicate a statistically significant response rate to TKI therapy within the EGFR mutated patients [37, 40, 42-44, 46]. These results indicate that EGFR positive pleural metastases have a similar response to TKI therapy as seen in other EGFR positive metastatic sites. It is, therefore, reasonable to manage patients with EGFR positive MPEs with TKI 
therapy and look for resolution before considering invasive procedures such as indwelling pleural catheter placement and/or pleurodesis. A lack of response or recurrence of a MPE following initial resolution with TKI therapy, however, should prompt repeat pleural fluid sampling to assess for change in EGFR mutation status and consideration of alternative therapies.

\section{EGFR detection in MPEs}

Patients with pleural effusion in the setting of lung cancer often require thoracentesis for diagnosis, staging and symptom management. Thoracentesis therefore provides a convenient, less-invasive, easily repeatable and relatively safe means of cell sampling that yields important clinical and therapeutic results. Although pleural fluid cytology is routinely performed when there is suspicion of malignancy, initial sampling is positive in only $50 \%$ of cases of MPE. Cell heterogeneity within the pleural fluid likely contributes to this low diagnostic yield, as inflammatory and mesothelial cells also contribute to the milieu. As such, it has been shown that malignant cell concentration in pleural fluid is only around $40 \%$ [48]. Diagnostic yield, however, increases by $17 \%$ with subsequent sampling, and is therefore the recommended approach to a suspected MPE by the American College of Chest Physicians (ACCP) [49]. In addition to routine cytology, it has been shown that molecular testing for specific gene mutations on very small samples of pleural fluid is feasible, and helpful clinically to identify patients who may benefit from targeted TKI therapy.

Certain EGFR mutations are associated with an increased response or lack of response to EGFR TKIs in NSCLC patients. EGRF gene exon 19 deletions, exon 21 mutation L858R (c.2573T $>$ G), exon 21 mutation L861Q (c.2582T $>\mathrm{A}$ ) and exon 18 mutation at amino acid location 719 (G719A, c.2156G $>$ C; G719S, 2155G $>$ A; and G719C, $2155 \mathrm{G}>\mathrm{T}$ ) are the most common mutations associated with increased response to TKIs $[50,51]$ The most common EGFR mutations associated with lack of response or resistance to EGFR TKIs are exon 20 mutation T790M (c.2369C $>$ T), exon 20 mutation S768I (c.2303G $>$ T), and identified insertions in exon 20 [52]. Certain patient characteristics are associated with EGFR mutations in NSCLC including females, East Asian descent, never smokers, and adenocarcinoma subtype [53]. This same population of patients has also been associated with a favorable response to TKI therapy [22]. Mutational analysis of pathologic specimens for EGFR, however, remains the only reliable way to determine the presence of EGFR mutations. Huang, et al. reported the first case of successful EGFR mutation determination from MPE sampling in 2005 using polymerase chain reaction (PCR), clinically correlated with a positive response to Gefitinib therapy [54]. Subsequent research has shown that DNA in pleural fluid can be used to detect EGFR mutations, and that mutation status predicts response to TKIs. [40, 42, 44, 55, 56].

In addition, discordance between primary tumor and metastatic lesions including MPE represents a unique challenge in terms of disease behavior, progression, and recurrence. A recent study comparing the EGFR mutation status between 37 primary NSCLCs and their corresponding metastatic (synchronous and metachronous) sites showed a discordance rate of $16.2 \%$ for all metastatic sites, and $14.3 \%$ amongst the pleural metastases specifically [57•]. This study further demonstrated that positive response to TKI inhibitors in the discordant pleural cases was associated with the EGFR mutation status of the pleural metastasis, not the primary tumor. Although this is a retrospective study involving a small cohort of patients, it highlights several important aspects of metastatic tumor biology and its potential clinical implications for repeat molecular testing of MPE following disease progression.

Current National Comprehensive Cancer Network (NCCN) guidelines recommend testing for EGFR mutations in NSCLC, but do not specify which method should be used to do so. Several tests currently exist, some of which have been studied either comparatively or in combination in attempts to identify a superior detection methodology (Table 2). A significant challenge specific to pleural fluid analysis is the heterogeneity of the sample, including varying ratios of normal and malignantcells. This makes the sensitivity of a chosen mutation detection assay critical so as to avoid high false negative rates. A standardized method for EGFR mutation detection in MPE has yet to be determined. Polymerase chain reaction (PCR), direct DNA sequencing, direct RNA sequencing, and immunohistochemistry are some of the methods that are currently being utilized and have been tested in isolation or in combination. In Fig. 1, we propose a testing algorithm for the evaluation of malignant pleural effusions.

\section{Methods for EGFR mutational analysis in MPE}

Polymerase chain reaction (PCR) and direct sequencing (Sanger)

One method used to directly sequence a designated target involves amplification by PCR to generate amplicons of the target gene. PCR exponentially amplifies a given target using forward and reverse primers. The PCR product of the given gene targeted area are then sequenced using direct sequencing, which involves dye-terminating fluorescent dideoxynucleotides (ddNTPs) that identify the order of the individual nucleotides for the given target. This method offers full characterization of the designed PCR product. 
Table 2 Pleural fluid variant analysis

\begin{tabular}{|c|c|c|c|}
\hline Methodology* & $\begin{array}{l}\text { DNA requirements } \\
\text { (ng)** }\end{array}$ & $\begin{array}{l}\text { Detect }<5 \% \\
\text { mutation } * * *\end{array}$ & Pros and cons \\
\hline Real-Time PCR & $1.0-100+$ & Yes & $\begin{array}{l}\text { Very sensitive method. Will only detect variants that have been designed targets of the } \\
\text { assay. }\end{array}$ \\
\hline $\begin{array}{l}\text { Direct Sequencing } \\
\text { (Sanger) }\end{array}$ & $3.0-3,000+$ & No & $\begin{array}{l}\text { Can detect all potential variants within the designed amplicon. Lower sensitivity than } \\
\text { the other two methodologies. }\end{array}$ \\
\hline $\begin{array}{l}\text { Massively Parallel } \\
\text { Sequencing (NGS) }\end{array}$ & $10-400+$ & Maybe & $\begin{array}{l}\text { Can detect all potential variants for designed amplicon. Sensitivity has been shown to } \\
\text { be greater than direct sequencing, but may not be as high as RT-PCR. }\end{array}$ \\
\hline
\end{tabular}

*Reproducibility of each methodology is dependent upon the individual laboratory it is performed in, and will vary slightly between laboratories **DNA requirements are based on the assay used; assays will vary in starting material required. For direct sequencing, DNA requirements will vary based on the size of the sequence and the number of cycles needed

*** Variant detection of less than $5 \%$ mutation in wild-type background

The size of the sequences fragment can vary based on design, but is on average relatively short, around 300 to 700 nucleotides long. In addition, due to primer binding issues, the first $15-40$ bases of the sequence is often poor. Also, the quality of the DNA sequence can deteriorate at the long-range nucleotides. The sensitivity of Sanger

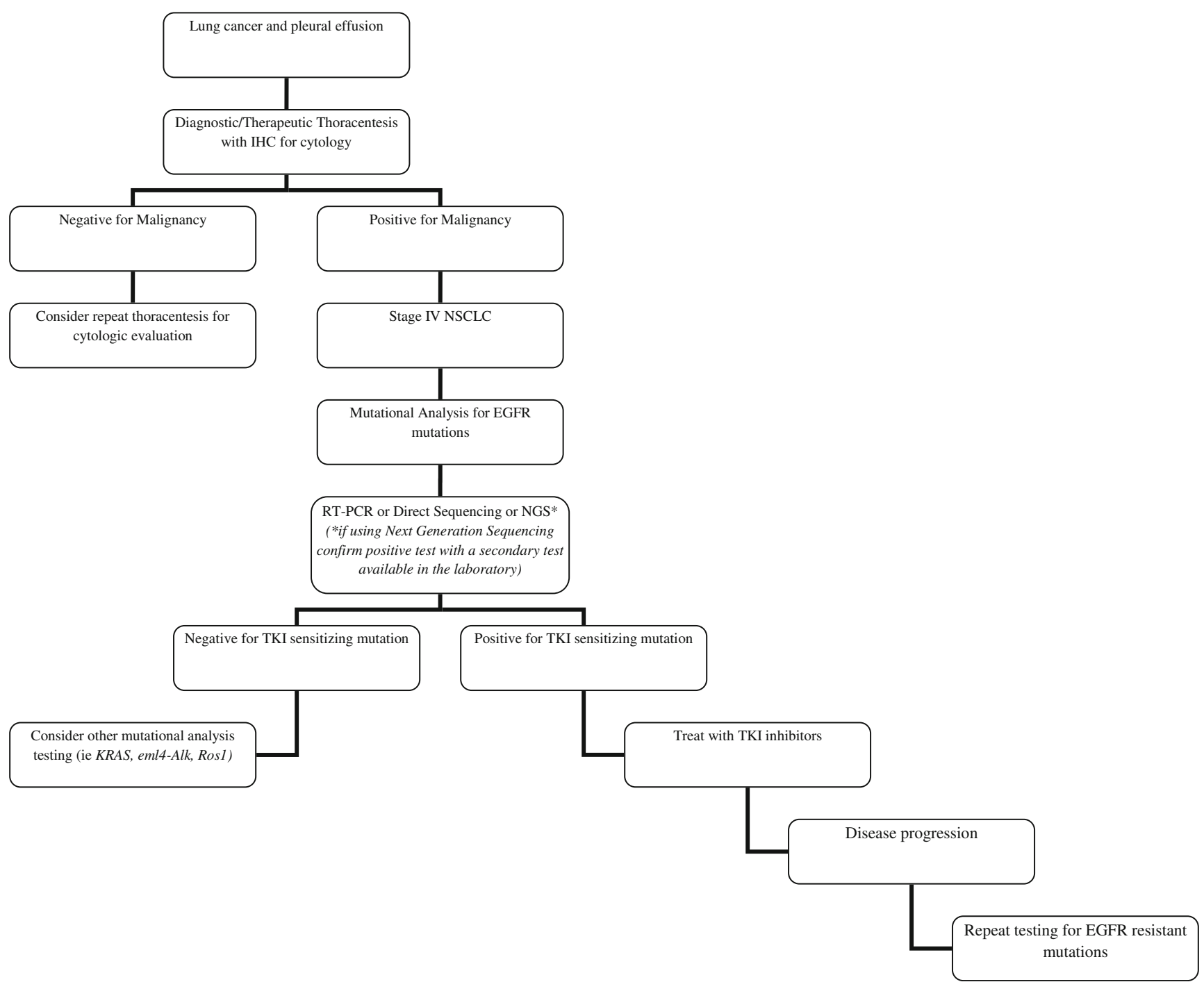

Fig. 1 Proposed algorithm for testing of malignant pleural effusion (MPE) 
sequencing is often lower, around $20 \%$, suggesting it may not be the ideal method for heterogenous samples of normal and malignant cells, such as those obtained from pleural fluid $[58,59]$.

Sequencing of cell-derived RNA has also been investigated and shows increased sensitivity to detect EGFR mutations $(67.3 \%$ vs. $44.7 \%)$ when compared to genomic DNA sequencing [46]. The sequencing technique is the same for both methodologies, except one uses RNA as a template as opposed to DNA, thus avoiding the additional cost and procedural complexity associated with highly sensitive mutant-enrichment PCR modalities. Disadvantages of using RNA targeting include its inherent lability as well as the abundant presence of RNase in biologic samples [56].

Massively parallel sequencing

Massively parallel sequencing, also known as next generation sequencing (NGS) or second/third generation sequencing, is a high throughput technology that allows for sequencing of millions of clonally amplified DNA templates at the same time. Depending on the platform used, read lengths can range from 35 to 700 nucleotides. This technology has been used for analysis of whole genomes, single genes, and panels of targeted gene regions. NGS sequencing has been found to be sensitive in the identification of EGFR mutations compared to Sanger sequencing for both bronchoalveolar lavage and pleural fluids. The sensitivity is dependent on the number of sequences generated for each sample [60-62]. While NGS was previously only used in research studies, it is becoming increasingly available in clinical laboratories.

\section{Real-time polymerase chain reaction (PCR)}

Real-time PCR is a molecular method used to amplify and quantify a targeted DNA. This technology is based on PCR, with the added advantage of the detection and quantification of the intended target. There are many techniques used to identify the target generated by the PCR. The two most common detection techniques include a fluorescent dye that intercalates into the intended DNA target generated by the forward and reverse primer and sequence specific fluorescent probes that hybridize to the DNA target amplicon and emit their fluorescence. This method tends to have a high sensitivity; however, it will only detect the variants specified through probe design and PCR enrichment strategies, such as amplified refractory mutation systems (ARMS), PCRrestriction fragment length polymorphism (PCR-RFLP), or peptide nucleic-acid locked nucleic-acid (PNA-LNA) PCR. ARMS technology has been shown to increase sensitivity for detecting EGFR mutations and may be used in conjunction with other methods such as direct sequencing $[42,63]$.
A comparative study of DNA sequencing and PCR-RFLP on both pleural fluid samples and cell-free supernatant demonstrated that $19 \%$ more EGFR mutations were found with a highly sensitive PCR assay [47].

\section{Immunohistochemistry}

Immunohistochemistry (IHC) is the process of detecting specific proteins within cells of a tissue sample using the concept of antibody/antigen binding. It is a well-established, easily performed, low-cost technique that may have an important role in the detection of EGFR mutations in MPEs. Mutant specific antibodies for the exon 19 deletion (E746-A750del) and the exon 21 mutation (L858R) are currently available for immunostaining [64]. This technique uses sections cut from cell block of pleural fluid that are prepared and incubated with the EGFR mutant-specific antibodies. Immunostaining is then evaluated for reactivity and graded based upon intensity. This modality was recently evaluated to determine its feasibility using RNA sequencing as the standard procedure for comparison. Results showed the combined sensitivity and specificity for the two mutantspecific antibodies to be $74 \%$ and $82 \%$ [56]. Additionally, those patients with mutations identified by IHC showed a similar response rate to TKIs when compared to those identified by the molecular method ( $67 \%$ vs. $72 \%$, respectively). However, a significant number of subjects with negative IHC staining ( $42 \%$ ) also showed a high response rate, highlighting the limited sensitivity of this modality. Although the available antibodies may identify the two most commonly encountered EGFR mutations, they do not target other less common mutations that may benefit from TKI treatment. Interobserver variability in assay interpretation also poses a problem in terms of increasing false positive rates. Similar limitations have been noted in tissue samples other than MPE, indicating that IHC should not be considered as first line testing for EGFR mutations at this time [65].

\section{Pleural fluid specimen preparation}

There are two common fixation methods for pleural fluid including ethanol fixation usually performed on slide smears and formalin fixation of cell blocks made from pleural fluid. Any of the above mentioned methods can be performed on pleural fluid from a slide smear or cell block. Due to the heterogeneous samples of normal and malignant cells, it is common practice to use additional tumor enrichment techniques, such as macrodissection, manual microdissection, or laser capture microdissection of the smear or cell block, in order to ensure sufficient malignant cell material for analysis. The use of formalin fixation is commonly 
used to preserve the structure and architecture of tissue or a cell; however, this causes DNA fragmentation and crosslinks DNA to other molecules. Formalin fixation leads to fragmentation of DNA whereas fixation with ethanol does not cause fragmentation resulting in longer strands of DNA for amplification or analysis.

\section{Conclusion}

As personalized medicine for NSCLC continues to evolve, the effective integration of cytologic, molecular and histologic testing to determine the most appropriate therapy for each individual patient will be of the utmost importance. While molecular testing is increasingly becoming the standard of clinical practice, there remains a need to standardize the method of EGFR detection in MPE to ensure a test or testing algorithm that maximizes sensitivity and specificity. This may be accomplished via a combination of testing modalities. Testing for EGFR is only the beginning as samples are also currently being tested for EML4-Alk translocation and there are a number of new molecular targets being investigated, such as ROS1, BRAF, KRAS, HER2, and PIK3CA [66]. As new therapies are developed directed at specific mutations, more testing of MPE will be required.

Conflict of Interest Clayton J. Shamblin declares no conflict of interest.

Nichole T. Tanner declares no conflict of interest.

Rolando Sanchez Sanchez declares no conflict of interest.

Julie A. Woolworth declares no conflict of interest.

Gerard A. Silvestri declares no conflict of interest.

\section{References}

Papers of particular interest, published recently, have been highlighted as:

- Of importance

1. Cancer facts and figures. Atlanta, GA: American Cancer Society; 2012

2. Network. NCC. NCCN Clinical Practice Guidelines in Oncology. Non-Small Cell Lung Cancer. V.2.2012; 2012

3. Brugger W, Triller N, Blasinska-Morawiec M, et al. Prospective molecular marker analyses of EGFR and KRAS from a randomized, placebo-controlled study of erlotinib maintenance therapy in advanced non-small-cell lung cancer. J Clin Oncol. 2011;29:4113-20.

4. Zhu CQ, da Cunha Santos G, Ding K, et al. Role of KRAS and EGFR as biomarkers of response to erlotinib in National Cancer Institute of Canada Clinical Trials Group Study BR.21. J Clin Oncol. 2008;26:4268-75.
5. Douillard JY, Shepherd FA, Hirsh V, et al. Molecular predictors of outcome with gefitinib and docetaxel in previously treated nonsmall-cell lung cancer: data from the randomized phase III INTEREST trial. J Clin Oncol. 2010;28:744-52.

6. - Mok TS, Wu YL, Thongprasert S, et al. Gefitinib or carboplatinpaclitaxel in pulmonary adenocarcinoma. N Engl J Med. 2009;361:947-57. This study is the first to show that EGFR mutations in NSCLC are associated with favorable responses to TKI therapy.

7. Inoue A, Kobayashi K, Usui K, et al. First-line gefitinib for patients with advanced non-small-cell lung cancer harboring epidermal growth factor receptor mutations without indication for chemotherapy. J Clin Oncol. 2009;27:1394-400.

8. Heffner JE, Nietert PJ, Barbieri C. Pleural fluid $\mathrm{pH}$ as a predictor of survival for patients with malignant pleural effusions. Chest. 2000;117:79-86.

9. Goldstraw P, Crowley J, Chansky K, et al. The IASLC Lung Cancer Staging Project: proposals for the revision of the TNM stage groupings in the forthcoming (seventh) edition of the TNM Classification of malignant tumours. J Thorac Oncol. 2007;2:70614.

10. Sahn SA. Pleural diseases related to metastatic malignancies. Eur Respir J. 1997;10:1907-13.

11. Stathopoulos GT, Kalomenidis I. Malignant pleural effusion: tumor-host interactions unleashed. Am J Respir Crit Care Med. 2012;186:487-92.

12. Yano S, Shinohara H, Herbst RS, et al. Production of experimental malignant pleural effusions is dependent on invasion of the pleura and expression of vascular endothelial growth factor/vascular permeability factor by human lung cancer cells. Am J Pathol. 2000;157:1893-903.

13. Yano S, Herbst RS, Shinohara H, et al. Treatment for malignant pleural effusion of human lung adenocarcinoma by inhibition of vascular endothelial growth factor receptor tyrosine kinase phosphorylation. Clin Cancer Res. 2000;6:957-65.

14. Shen YC, Liu MQ, Wan C, et al. Diagnostic accuracy of vascular endothelial growth factor for malignant pleural effusion: a metaanalysis. Exp Ther Med. 2012;3:1072-6.

15. Marshall HM, Leong SC, Bowman RV, et al. The science behind the 7 th edition tumour, node, metastasis staging system for lung cancer. Respirology. 2012;17:247-60.

16. Ou SH, Zell JA. Validation study of the proposed IASLC staging revisions of the $\mathrm{T} 4$ and $\mathrm{M}$ non-small cell lung cancer descriptors using data from 23,583 patients in the California Cancer Registry. $\mathrm{J}$ Thorac Oncol. 2008;3:216-27.

17. Morgensztern D, Waqar S, Subramanian J, et al. Prognostic impact of malignant pleural effusion at presentation in patients with metastatic non-small-cell lung cancer. J Thorac Oncol. 2012;7:1485-9.

18. Wu SG, Yu CJ, Tsai MF, et al. Survival of lung adenocarcinoma patients with malignant pleural effusion. Eur Respir J. 2012;

19. Keedy VL, Temin S, Somerfield MR, et al. American Society of Clinical Oncology provisional clinical opinion: epidermal growth factor receptor (EGFR) mutation testing for patients with advanced non-small-cell lung cancer considering first-line EGFR tyrosine kinase inhibitor therapy. J Clin Oncol. 2011;29:2121-7.

20. Fukuoka M, Wu YL, Thongprasert S, et al. Biomarker analyses and final overall survival results from a phase III, randomized, open-label, first-line study of gefitinib versus carboplatin/paclitaxel in clinically selected patients with advanced non-small-cell lung cancer in Asia (IPASS). J Clin Oncol. 2011;29:2866-74.

21. Inoue $\mathrm{A}$, Kobayashi $\mathrm{K}$, Maemondo $\mathrm{M}$, et al. Updated overall survival results from a randomized phase III trial comparing gefitinib with carboplatin-paclitaxel for chemo-naive non-small cell lung cancer with sensitive EGFR gene mutations (NEJ002). Ann Oncol. 2013;24:54-9. 
22. Lee JS, Park K, Kim SW, et al. A randomized phase III study of gefitinib (IRESSA ${ }^{\mathrm{TM}}$ ) versus standard chemotherapy (gemcitabine plus cisplatin) as a first-line treatment for never-smokers with advanced or metastatic adenocarcinoma of the lung. J Thorac Oncol. 2009;4:S283-4.

23. Maemondo M, Inoue A, Kobayashi K, et al. Gefitinib or chemotherapy for non-small-cell lung cancer with mutated EGFR. N Engl J Med. 2010;362:2380-8.

24. Mitsudomi T, Morita S, Yatabe Y, et al. Gefitinib versus cisplatin plus docetaxel in patients with non-small-cell lung cancer harbouring mutations of the epidermal growth factor receptor (WJTOG3405): an open label, randomised phase 3 trial. Lancet Oncol. 2010;11:121-8.

25. Mitsudomi T, Morita S, Yatabe Y, et al. Updated overall survival results of WJTOG 3405, a randomized phase III trial comparing gefitinib $(\mathrm{G})$ with cisplatin plus docetaxel $(\mathrm{CD})$ as the first-line treatment for patients with non-small cell lung cancer harboring mutations of the epidermal growth factor receptor (EGFR). J Clin Oncol. 30. 2012; (suppl; abstr 7521) 2012.

26. - Rosell R, Carcereny E, Gervais R, et al. Erlotinib versus standard chemotherapy as first-line treatment for European patients with advanced EGFR mutation-positive non-small-cell lung cancer (EURTAC): a multicentre, open-label, randomised phase 3 trial. Lancet Oncol. 2012;13:239-46. This study highlights the importance of routine testing for EGFR mutations with advanced NSCLC and first-line therapy with TKIs.

27. Zhou C, Wu YL, Chen G, et al. Erlotinib versus chemotherapy as first-line treatment for patients with advanced EGFR mutationpositive non-small-cell lung cancer (OPTIMAL, CTONG-0802): a multicentre, open-label, randomised, phase 3 study. Lancet Oncol. 2011;12:735-42.

28. Yang JC, Schuler MH, Yamamoto N, et al. LUX-Lung 3: A randomized, open-label, phase III study of afatinib versus pemetrexed and cisplatin as first-line treatment for patients with advanced adenocarcinoma of the lung harboring EGFR-activating mutations. J Clin Oncol. 2012; supp 30:abstr LBA7500

29. Jacot W, Bessis D, Jorda E, et al. Acneiform eruption induced by epidermal growth factor receptor inhibitors in patients with solid tumours. Br J Dermatol. 2004;151:238-41.

30. Herbst RS, Prager D, Hermann R, et al. TRIBUTE: a phase III trial of erlotinib hydrochloride (OSI-774) combined with carboplatin and paclitaxel chemotherapy in advanced non-small-cell lung cancer. J Clin Oncol. 2005;23:5892-9.

31. Shepherd FA, Rodrigues Pereira J, Ciuleanu T, et al. Erlotinib in previously treated non-small-cell lung cancer. N Engl J Med. 2005;353:123-32.

32. Jackman D, Pao W, Riely GJ, et al. Clinical definition of acquired resistance to epidermal growth factor receptor tyrosine kinase inhibitors in non-small-cell lung cancer. J Clin Oncol. 2010;28:35760 .

33. Balak MN, Gong Y, Riely GJ, et al. Novel D761Y and common secondary T790M mutations in epidermal growth factor receptormutant lung adenocarcinomas with acquired resistance to kinase inhibitors. Clin Cancer Res. 2006;12:6494-501.

34. Costa DB, Schumer ST, Tenen DG, et al. Differential responses to erlotinib in epidermal growth factor receptor (EGFR)-mutated lung cancers with acquired resistance to gefitinib carrying the L747S or T790M secondary mutations. J Clin Oncol. 2008;26:1182-4. author reply $1184-1186$.

35. Belalcazar A, Azana D, Perez CA, et al. Targeting the Met pathway in lung cancer. Expert Rev Anticancer Ther. 2012;12:519-28.

36. Eberhard DA, Giaccone G, Johnson BE. Biomarkers of response to epidermal growth factor receptor inhibitors in Non-Small-Cell Lung Cancer Working Group: standardization for use in the clinical trial setting. J Clin Oncol. 2008;26:983-94.
37. Wu SG, Gow $\mathrm{CH}$, Yu CJ, et al. Frequent epidermal growth factor receptor gene mutations in malignant pleural effusion of lung adenocarcinoma. Eur Respir J. 2008;32:924-30.

38. Froudarakis ME. Pleural effusion in lung cancer: more questions than answers. Respiration. 2012;83:367-76.

39. Asano H, Toyooka S, Tokumo M, et al. Detection of EGFR gene mutation in lung cancer by mutant-enriched polymerase chain reaction assay. Clin Cancer Res. 2006;12:43-8.

40. Hung MS, Lin CK, Leu SW, et al. Epidermal growth factor receptor mutations in cells from non-small cell lung cancer malignant pleural effusions. Chang Gung Med J. 2006;29:373-9.

41. Jian G, Songwen Z, Ling Z, et al. Prediction of epidermal growth factor receptor mutations in the plasma/pleural effusion to efficacy of gefitinib treatment in advanced non-small cell lung cancer. J Cancer Res Clin Oncol. 2010;136:1341-7.

42. Kimura H, Fujiwara Y, Sone T, et al. High sensitivity detection of epidermal growth factor receptor mutations in the pleural effusion of non-small cell lung cancer patients. Cancer Sci. 2006;97:642-8.

43. Kimura H, Fujiwara Y, Sone T, et al. EGFR mutation status in tumour-derived DNA from pleural effusion fluid is a practical basis for predicting the response to gefitinib. $\mathrm{Br} \mathrm{J}$ Cancer. 2006;95:1390-5.

44. Soh J, Toyooka S, Aoe K, et al. Usefulness of EGFR mutation screening in pleural fluid to predict the clinical outcome of gefitinib treated patients with lung cancer. Int $\mathrm{J}$ Cancer. 2006;119:2353-8.

45. Tanaka T, Nagai Y, Miyazawa H, et al. Reliability of the peptide nucleic acid-locked nucleic acid polymerase chain reaction clampbased test for epidermal growth factor receptor mutations integrated into the clinical practice for non-small cell lung cancers. Cancer Sci. 2007;98:246-52.

46. Tsai TH, Su KY, Wu SG, et al. RNA is favourable for analysing EGFR mutations in malignant pleural effusion of lung cancer. Eur Respir J. 2012;39:677-84.

47. Zhang X, Zhao Y, Wang M, et al. Detection and comparison of epidermal growth factor receptor mutations in cells and fluid of malignant pleural effusion in non-small cell lung cancer. Lung Cancer. 2008;60:175-82.

48. Sahn SA. Malignancy metastatic to the pleura. Clin Chest Med. 1998;19:351-61.

49. Rivera MP, Mehta AC. Initial diagnosis of lung cancer: ACCP evidence-based clinical practice guidelines (2nd edition). Chest. 2007;132:131S-48S

50. Pao W, Miller VA. Epidermal growth factor receptor mutations, small-molecule kinase inhibitors, and non-small-cell lung cancer: current knowledge and future directions. J Clin Oncol. 2005;23:2556-68.

51. Sharma SV, Bell DW, Settleman J, et al. Epidermal growth factor receptor mutations in lung cancer. Nat Rev Cancer. 2007;7:169 81.

52. Yasuda H, Kobayashi S, Costa DB. EGFR exon 20 insertion mutations in non-small-cell lung cancer: preclinical data and clinical implications. Lancet Oncol. 2012;13:e23-31.

53. Giaccone G, Rodriguez JA. EGFR inhibitors: what have we learned from the treatment of lung cancer? Nat Clin Pract Oncol. 2005;2:554-61.

54. Huang MJ, Lim KH, Tzen CY, et al. EGFR mutations in malignant pleural effusion of non-small cell lung cancer: a case report. Lung Cancer. 2005;49:413-5.

55. Soh J, Toyooka S, Ichihara S, et al. EGFR mutation status in pleural fluid predicts tumor responsiveness and resistance to gefitinib. Lung Cancer. 2007;56:445-8.

56. Tsai TH, Wu SG, Chang YL, et al. Effusion immunocytochemistry as an alternative approach for the selection of first-line targeted therapy in advanced lung adenocarcinoma. J Thorac Oncol. 2012;7:993-1000. 
57. • Han HS, Eom DW, Kim JH, et al. EGFR mutation status in primary lung adenocarcinomas and corresponding metastatic lesions: discordance in pleural metastases. Clin Lung Cancer. 2011;12:380-6. This study showed a discordance between EGFR mutation status in primary and metastatic sites in a significant number of lung adenocarcinomas, and highlights the importance of repeat sampling for mutational analysis in such cases.

58. Smouse JH, Cibas ES, Janne PA, et al. EGFR mutations are detected comparably in cytologic and surgical pathology specimens of nonsmall cell lung cancer. Cancer. 2009;117:67-72.

59. Thunnissen E, Kerr KM, Herth FJ, et al. The challenge of NSCLC diagnosis and predictive analysis on small samples. Practical approach of a working group. Lung Cancer. 2012;76:1-18.

60. Buttitta F, Felicioni L, Del Grammastro M, et al. Effective Assessment of Egfr Mutation Status in Bronchoalveolar Lavage and Pleural Fluids by Next Generation Sequencing. Clin Cancer Res. 2012;
61. Thomas RK, Nickerson E, Simons JF, et al. Sensitive mutation detection in heterogeneous cancer specimens by massively parallel picoliter reactor sequencing. Nat Med. 2006;12:852-5.

62. Querings S, Altmuller J, Ansen S, et al. Benchmarking of mutation diagnostics in clinical lung cancer specimens. PLoS One. 2011;6: e19601.

63. Liu Y, Liu B, Li XY, et al. A comparison of ARMS and direct sequencing for EGFR mutation analysis and tyrosine kinase inhibitors treatment prediction in body fluid samples of non-smallcell lung cancer patients. J Exp Clin Cancer Res. 2011;30:111.

64. Yu J, Kane S, Wu J, et al. Mutation-specific antibodies for the detection of EGFR mutations in non-small-cell lung cancer. Clin Cancer Res. 2009;15:3023-8.

65. Brevet M, Arcila M, Ladanyi M. Assessment of EGFR mutation status in lung adenocarcinoma by immunohistochemistry using antibodies specific to the two major forms of mutant EGFR. J Mol Diagn. 2010;12:169-76.

66. Zimmermann S, Peters S. Going beyond EGFR. Ann Oncol. 2012;23 Suppl 10:x197-203. 